\title{
Desarrollos preclínicos de vacunas profilácticas contra la Enfermedad de Chagas basadas en Transialidasa.
}

\author{
Pre-clinical development of Trans-sialidase based \\ prophylactic vaccines against Chagas disease.
}

\author{
Brenda Dinatale*, Camila Bulfoni Balbi*, Florencia B. González, Ana R. Pérez, María F. Pacini. \\ *Autoría compartida
}

Instituto de Inmunología Clínica y Experimental de Rosario (CONICET-UNR). Rosario; Argentina.

Autor por correspondencia: María Florencia Pacini — pacini@idicer-conicet.gob.ar

Conflicto de intereses: no presenta.

\section{Resumen}

La Enfermedad de Chagas (ECh), ocasionada por el parásito flagelado Trypanosoma cruzi (T. cruzi), es una de las parasitosis de mayor impacto en la Salud Pública de Latinoamérica. Si bien actualmente existen medidas de prevención como el tamizaje en bancos de sangre, el control a las embarazadas y el control vectorial, aún se requiere de estrategias más eficaces para evitar nuevos casos. Una de estas posibles estrategias es el desarrollo de una vacuna profiláctica contra T. cruzi. Desde el descubrimiento de la enfermedad en 1909, se han evaluado diferentes vacunas experimentales, pero aún no se ha logrado el desarrollo clínico de una formulación efectiva contra el parásito. En este artículo realizamos una revisión bibliográfica acerca de las distintas estrategias de vacunación que se evaluaron hasta la actualidad y, particularmente, el uso de la enzima Transialidasa (TS) como antígeno vacunal. También abordamos distintos aspectos de la superfamilia de la TS, como la clasificación de las distintas proteínas, sus características funcionales y su rol en la infección por T. cruzi.

A lo largo de 100 años se han abordado y perfeccionado una gran diversidad de estrategias vacunales contra T. cruzi, lo cual permite augurar el salto desde el campo pre—clínico al desarrollo clínico de una vacuna efectiva en un futuro cercano.

Palabras claves: Vacuna. Transialidasa. Enfermedad de Chagas.

\begin{abstract}
Chagas disease (ChD) is caused by the flagellated parasite Trypanosoma cruzi (T. cruzi), representing a serious public health in Latin America. Currently, there are prevention measures such as blood screening, control of pregnant women and vector control, but more effective strategies are still required to prevent new cases. One of these strategies is the development of a prophylactic vaccine against T. cruzi. Since the discovery of the disease in 1909, different experimental vaccines have been evaluated, but the clinical development of an effective formulation against the parasite has not yet been achieved. Here, we review the different vaccination strategies that have been evaluated to date, and particularly, the use of the enzyme Trans—-sialidase (TS) as a vaccine antigen.
\end{abstract}


We also address different aspects of the TS superfamily, such as the classification of the different proteins, their functional characteristics, and their role in T. cruzi infection.

Over 100 years, a great diversity of vaccine strategies against T. cruzi have been approached and refined, auguring that in the near future it will be possible to cross from the pre-clinical to the clinical field.

Keywords: Vaccine. Trans-sialidase. Chagas disease.

\section{Generalidades acerca de la Enfermedad de Chagas}

La Enfermedad de Chagas (ECh), ocasionada por el parásito flagelado Trypanosoma cruzi (T. cruzi), es una de las parasitosis de mayor impacto en la Salud Pública de América Latina. Sumado a esto, los actuales fenómenos de globalización y flujo de personas entre áreas endémicas y no endémicas provocaron la expansión de esta enfermedad a otras regiones del mundo (1).

Los registros más recientes reportan que aproximadamente 8 millones de personas están infectadas, con un promedio de 28 mil nuevos casos y 12 mil muertes cada año, mientras que 90 millones se encuentran en riesgo de contraer la infección (1).

La ECh es una zoonosis, transferida naturalmente a mamíferos (hombres, animales domésticos y salvajes) por insectos triatominos, que constituyen los vectores de la enfermedad. Estos potenciales vectores alcanzan más de130 especies, yes Triatomainfestans, comúnmente conocido como vinchuca, el vector predominante en Argentina (2,3). Este tipo de transmisión representa aproximadamente el $70 \%$ de las infecciones en las áreas endémicas, el resto de los casos se deben a transmisión congénita o vertical (26\%); transfusión sanguínea o trasplante de órganos desde un donante infectado (1\%); consumo de alimentos o bebidas contaminadas con heces del vector (1\%); o accidentes de laboratorio (1\%) (4). Si bien la vía de infección oral es la menos estudiada y posiblemente subestimada, suele causar brotes en los que se evidencia una forma aguda muy sintomática con una alta mortalidad (5).

El parásito a lo largo de su ciclo de vida alterna entre el insecto vector y huéspedes mamíferos. Según el hospedero en el que se encuentre, T. cruzi adopta diferentes formas biológicas, las cuales se caracterizan por las posiciones relativas del flagelo, el cinetoplasto y el núcleo; y son funcionalmente distintas (6,7). La forma epimastigote se localiza en el tracto digestivo del vector, se identifica por presentar un cinetoplasto alargado y es una forma replicativa $(7,8)$. La forma tripomastigote se caracteriza por presentar un cinetoplasto localizado por detrás del núcleo, el flagelo nace en su proximidad y emerge por un costado del cuerpo del parásito. Los tripomastigotes están presentes en la circulación de mamíferos y es la forma que ingiere el vector. Otra forma, llamada tripomastigote metacíclico, se encuentra solo en la ampolla rectal del vector y representa la forma infectiva en mamíferos. Estas últimas dos formas tripomastigote carecen de capacidad replicativa $(7,8)$. Por último, la forma amastigote, de localización intracitoplasmática, carece de flagelo libre, es de forma esférica u ovalada y se replica por fisión binaria en mamíferos (7).

Una vez dentro del intestino del vector, los epimastigotes tienen la capacidad de replicarse y diferenciarse a tripomastigote metacíclico, que es la forma infecciosa para el mamífero. En el huésped mamífero puede invadir diferentes células nucleadas y una vez allí se diferencia a la forma amastigote. El estadio amastigote puede replicarse y diferenciarse en tripomastigote sanguíneo, el cual puede seguir invadiendo otras células del huésped o ser ingerido por el vector dando inicio nuevamente al ciclo (Figura 1). 


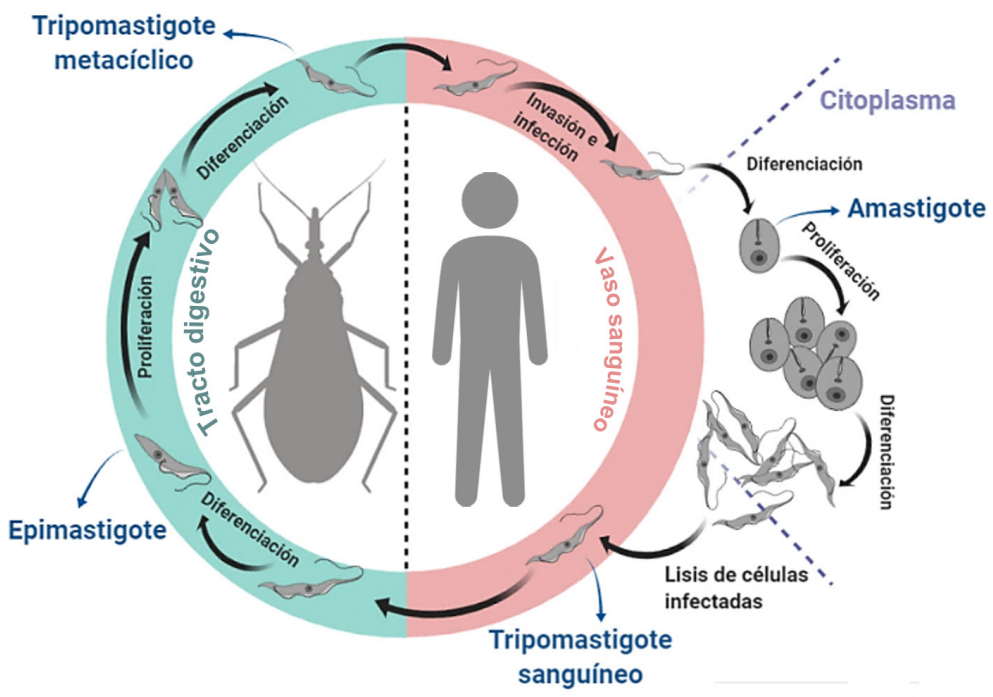

Figura 1. Ciclo de vida de Trypanosoma cruzi. En el esquema se ilustra el ciclo de vida de Trypanosoma cruzi, que incluye su estadio en el insecto triatomino y en los mamíferos (en este caso los seres humanos). A lo largo del mismo se detallan las diferentes formas biológicas de este patógeno: epimastigote, tripomastigote metacíclico (triatomino), amastigote y tripomastigote sanguíneo (mamífero).

En su mayoría, las personas infectadas por transmisión vectorial desarrollan una fase aguda asintomática y solo alrededor del 1\% de ellos experimenta síntomas específicos severos (4). Después de un tiempo variable (que puede ir de 10 a 30 años), entre el 20-30\% de las personas infectadas progresan a la ECh crónica, que se caracteriza por mega síndromes que involucran el corazón y/o el tracto digestivo. Estas condiciones son responsables de las discapacidades y muertes observadas en los individuos infectados (9).

El tratamiento de los pacientes infectados requiere de la administración prolongada de drogas conocidas como Benznidazol o Nifurtimox, las que suelen presentar severos efectos adversos y que además sólo son probadamente eficaces durante la fase aguda de la enfermedad (10). Si bien actualmente existen ciertas medidas de prevención como el tamizaje en bancos de sangre, el control a las embarazadas y el control vectorial, aún se requieren de estrategias más eficaces para evitar nuevos casos. Una de estas posibles estrategias es el desarrollo de una vacuna profiláctica contra T. cruzi (11).

Cuando el parásito invade a las células del huésped, juegan un papel importante las células de la inmunidad innata, como los macrófagos, células natural killer o asesinas naturales (NK) y células dendríticas (CDs); las cuales producen citocinas proinflamatorias o de tipo T helper o cooperadoras 1 (Th1), como Interleucina (IL) - 12, Factor de Necrosis Tumoral (TNF)—a e Interferón (IFN) - $\gamma$ y moléculas efectoras (entre ellas las especies reactivas del nitrógeno u oxígeno) que se encargarían de controlar la replicación del parásito. Estas células innatas, principalmente las CDs, promueven la diferenciación y la expansión clonal de células T CD4, T CD8 y células B plasmáticas, a partir de la secreción de IL-12. A su vez, las células T CD4 y CD8 secretan al medio IFN- $\gamma$ que activa los mecanismos efectores en los macrófagos para destruir los amastigotes y los tripomastigotes fagocitados, mientras que la actividad citotóxica de las células T CD8 destruye las células infectadas por amastigotes intracelulares. Además, los anticuerpos de tipo IgG2a producidos por las células B opsonizan al parásito facilitando su fagocitosis (12). Recientemente se observó que las células Th17 pueden proteger directamente las células infectadas con T. cruzi a través de la inducción de NADPH oxidasa dependiente de IL-17A en macrófagos, y a su vez proporcionar ayuda indirecta a través de la activación dependiente de IL—21 de las células T CD8. Por lo tanto, para alcanzar una inmunidad protectora contra T. cruzi se necesitan mecanismos de la inmunidad innata y de la adaptativa. En líneas generales, se considera que una respuesta protectora efectiva debe ser del tipo Th1/Th2/Th17 y comprender tanto una respuesta celular como humoral específica (12). 


\section{Historia del desarrollo de vacunas profilácticas para la Enfermedad de Chagas}

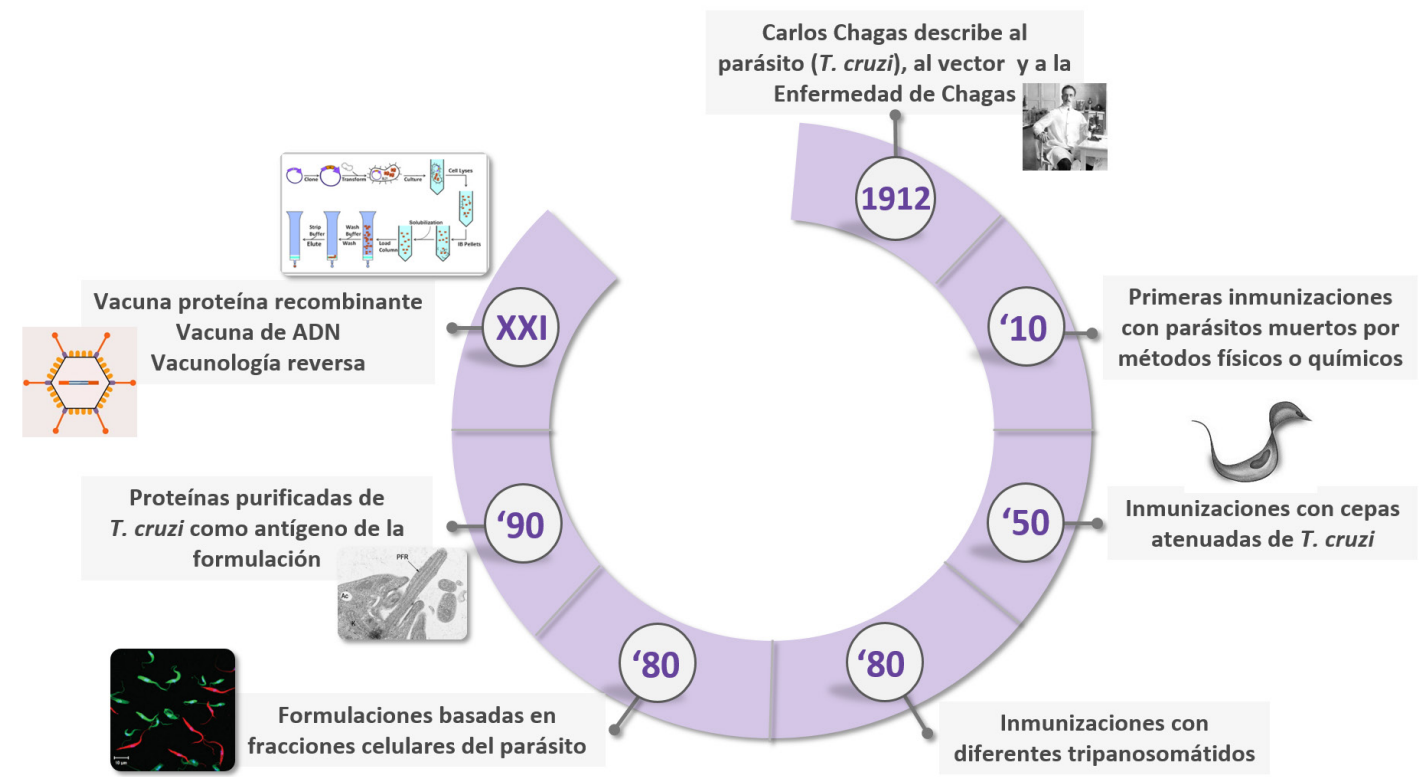

Figura 2. Historia del desarrollo de vacunas profilácticas para la Enfermedad de Chagas. Esquema cronológico sobre las estrategias evaluadas para el desarrollo de vacunas profilácticas contra T. cruzi, desde su descubrimiento hasta la actualidad.

La idea de desarrollar una vacuna contra T. cruzi surgió en 1912, cuando Blanchard demostró que los animales que sobrevivían a la fase aguda eran resistentes a las re-infecciones. Desde ese entonces se han probado a lo largo de los años numerosas estrategias con el objetivo de desarrollar una vacuna contra esta enfermedad (Figura 2).

Las primeras inmunizaciones se llevaron a cabo con tripanosomas muertos, obtenidos por distintos métodos tanto químicos como físicos, dentro de los cuales podemos mencionar diversas estrategias desarrolladas a lo largo de los años como el tratamiento con Timerosal o Formalina (químicos), sonicación, congelado y descongelado, pulverización, irradiación y diferencia de presión (físicos). Los primeros intentos de inmunización dieron resultados desalentadores ya que estas vacunas proporcionaban bajo grado de protección. En parte, esto podría haber estado relacionado con la pérdida de epítopes protectores durante la inactivación y/o el fraccionamiento (13).

A finales del siglo XX, se llevaron a cabo inmunizaciones experimentales con tripanosomátidos relacionados como T. rangeli o parásitos con cierta similitud antigénica como Phytomonas serpens, los cuales no son patogénicos para seres humanos. Estos estudios mostraron una reducción significativa de la parasitemia y un aumento en la supervivencia ante la infección posterior con $\mathrm{T}$. cruzi $(14,15)$.

Entre la década de los 80 y los 90, se intentó identificar porciones inmunogénicas, proteínas o glicoproteínas del parásito capaces de inducir una respuesta inmune protectora. En una primera instancia se realizaron diversos estudios de fraccionamiento celular. Así, se identificó que una fracción flagelar de T. cruzi era capaz de disminuir la parasitemia (16), y más adelante se lograron aislar diferentes glicoproteínas (GP) de la superficie del parásito que exhibieron un buen grado de protección, tales como las GP90, GP70 (17) y las proteínas 45 kDa y de 68 kDa emulsionadas en un derivado de saponina llamado Quil A (18). Incluso, una proteína $72 \mathrm{kDa}$ obtenida a partir de epimastigote generó un título elevado de IgG, inmunidad celular específica y una disminución significativa de la parasitemia (19). También se identificaron los antígenos de la superfamilia de la transialidasa (TS) (737 genes), las mucinas (662 genes), las proteínas de superficie asociadas a mucinas (MASP, 944 genes), GP63 (174 genes) (20), la proteína reguladora del complemento (CRP) (21), la cisteína proteasa lisosomal cruzipaína $(\mathrm{Cz})(22)$, la proteína de unión a calcio flagelar (FCaBP o Tc24) (23,24), GP90, GP82 (25) y TC52 (26).

Hoy en día y gracias al desarrollo de la tecnología del ADN recombinante muchas de estas proteínas pueden sintetizarse para su posterior uso en el desarrollo de vacunas (27-30).

Asimismo, también se han utilizado diversos microorganismos o patógenos recombinantes como vehículos para la administración del inmunógeno, los cuales suelen conocerse como "sistemas de 
delivery". En estesentido, se han probado sistemas de "delivery" basados en adenovirus recombinantes de tipo 5 humanos no replicantes (Ad5), Salmonella y Lactococcus lactis. (31,32).

Más recientemente, el desarrollo de las "ómicas" (tales como genómica y proteómica), junto con distintas herramientas bioinformáticas, permitieron detectar nuevos y potenciales inmunógenos. Este enfoque se conoce actualmente como "vacunología inversa" (33). Con esta estrategia se detectaron nuevas proteínas secretadas o ancladas a la membrana que podrían funcionar como buenos antígenos vacunales (34).

\section{La familia de la Transialidasa}

Uno de los inmunógenos más importante de T. cruzi es la enzima TS, considerada un factor de virulencia clave. Esta enzima participa en el proceso de trans-sialidación, que consiste en la transferencia de residuos de ácidos siálicos (AcsS), específicamente el monosacárido de los sialilglicoconjugados, desde la superficie de las células de mamíferos hacia $\beta$-galactosas terminales localizadas sobre su propia superficie $(35,36)$. Los AcsS son una familia de monosacáridos que están presentes en la superficie de todas las células de mamíferos y que confieren diversas actividades biológicas a glicoproteínas y glicolípidos, tales como la promoción de las interacciones célula—célula o el enmascaramiento de ciertos sitios debido a su elevada carga negativa (37). A diferencia de otros microorganismos, T. cruzi no puede sintetizar "de novo" AcsS y por tal motivo los recupera de las células del huésped.

Las TSs son una superfamilia codificada por 1430 genes, entre ellos se encuentran genes que codifican para TSs enzimáticamente activas (en donde el dominio catalítico está altamente conservado) y genes que codifican para formas inactivas, ya que carecen del dominio catalítico o bien que constituyen pseudogenes (20,38). Las TSs se distribuyen en diferentes regiones del parásito como puede ser a lo largo del cuerpo celular, el flagelo y el bolsillo flagelar $(39,40)$.

Recientemente, esta gran familia fue subdividida en ocho grupos en función de la similitud de secuencias y las propiedades funcionales, así como también de la presencia o ausencia de varios motivos muy conservados. Uno de ellos es el motivo VTVxNVxLYNR, localizado en el extremo Cterminal, característico de todos los miembros de TS. Otros dos motivos, FRIP (xRxP) y caja ASP también se pueden encontrar en varios grupos de la superfamilia de la TS. El motivo FRIP, que está más cerca del N-terminal, participa en la unión del grupo carboxilato del AcsS (41). Si bien se desconoce su función, cabe señalar que la caja ASP se encuentra en proteínas secretadas y en proteínas que actúan sobre los carbohidratos o interactúan con ellos (42). En esta clasificación las TSs activas se encuentran reunidas en el grupo I y el resto de los miembros de la familia distribuidos en los grupos restantes (Figura 3A) (43). 
A

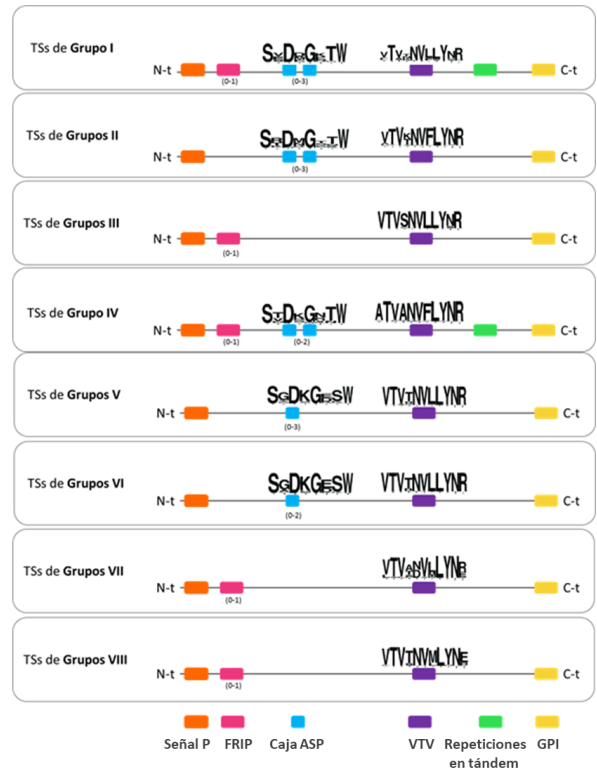

B

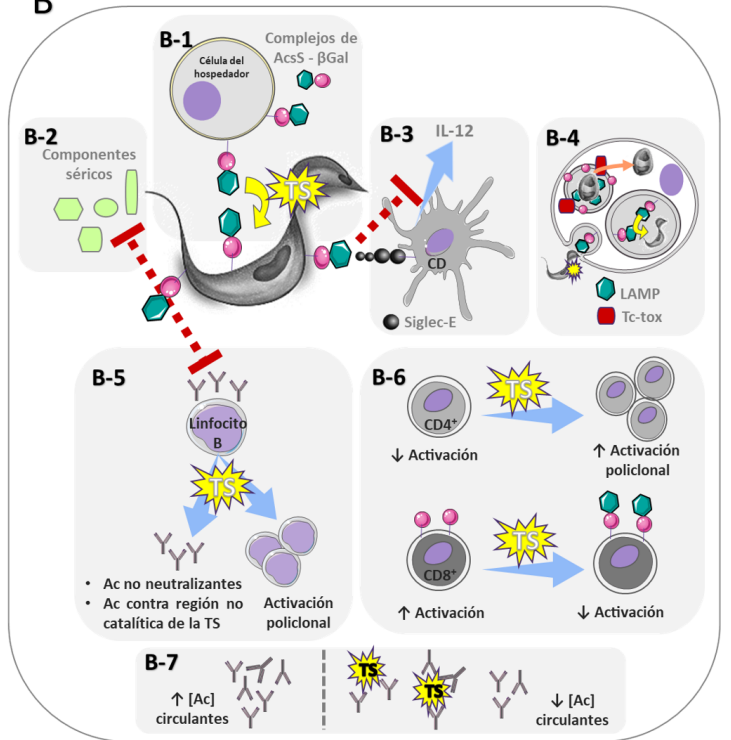

Figura 3. Transialidasa (TS). A) Clasificación de la superfamilia de la TS. Esquema comparativo de las secuencias de las TS pertenecientes a los grupos I a VIII, en donde se visualizan la Caja Asp y el motivo VTVxNVxLYNR. Los números entre paréntesis indican el número de apariciones de un motivo dado. Adaptado de Freitas, et al 2011 (43). B) Mecanismos de evasión del sistema inmune mediado por TS: B-1). El parásito cubre su superficie de moléculas de ácidos siálicos (AcsS), mediante la acción Transialidasa, lo cual le confiere cargas negativas. B-2). La cubierta protectora de moléculas de AcsS elude los efectos del sistema del complemento. B-3) Supresión de la producción de IL-12 en las CDs al interactuar a través de sus motivos Siglec-E con los AcsS de la superficie de T. cruzi. B-4) T. cruzi invade las células del hospedador y su internalización conduce a la formación de la vacuola parasitófora, cuya membrana interna se encuentra enriquecida de proteínas LAMP altamente sialidadas. El pH ácido de esta vacuola favorece la transferencia de AcsS de las proteínas LAMP a la superficie del parásito, lo que genera una mayor susceptibilidad a la lisis de la vesícula mediada por Tc-Tox, una proteína del parásito que forma poros en la membrana, permitiendo así que T. cruzi escape desde la misma hacia el citoplasma celular. B—5) La región SAPA de la enzima TS promueve la producción de anticuerpos (Ac) no neutralizantes contra sitios distantes a la región catalítica. En paralelo se produce una activación policlonal de los linfocitos B. Los AcsS transferidos a la superficie del parásito repelen los anticuerpos generados debido a su carga negativa. B-6) La TS es capaz de activar en forma policlonal a los linfocitos T CD4. Además, la TS es capaz de sialidar la superficie de los linfocitos T CD8 activados, lo cual limita su capacidad efectora. B-7) La TS no solo se encuentra en la superficie de T. cruzi, sino que durante la infección puede escindirse el ancla GPI que la une a la superficie del mismo, y en consecuencia se libera TS soluble. Esta última sería capaz de formar inmunocomplejos con Ac específicos anti-TS, lo que conduce a disminuir la concentración efectiva de Ac circulantes $(\downarrow[$ Ac] $)(94,95)$. Figura adaptada de Nardy, et al 2016 (77).

El grupo I está constituido por enzimas activas, estas pueden poseer no sólo actividad transialidasa sino también neuraminidasa, función que consiste en la remoción del ácido siálico mediante la incorporación de una molécula de agua. Los miembros del grupo I son: TcNA (neuraminidasa), TS-SAPA (antígeno de excreción de fase aguda), y TS—epi (44-46). Las enzimas TS—SAPA y TcNA tienen funciones activas de transialidasa y neuraminidasa y se expresan en los tripomastigotes sanguíneos (47). Estas enzimas contienen dos regiones principales, una región catalítica $\mathrm{N}$-terminal y una extensión $\mathrm{C}$-terminal, caracterizada por la presencia de repeticiones de 12 aminoácidos en tándem denominada justamente SAPA, la cual difiere en tamaño entre TS-SAPA y TcNA (48). Ambas proteínas están ancladas en la membrana plasmática por glicosilfosfatidilinositol (GPI) (47,49). A diferencia de estas dos, TS-epi sólo se expresa en la forma epimastigote, carece de repeticiones SAPA y no está anclado a la membrana por GPI. En este caso, su anclaje depende de la presencia de un dominio transmembrana seguido de una sección hidrófila en C-terminal (50).

El grupo II comprende glicoproteínas de superficie GP85 denominadas: ASP—1, ASP—2, TSA—1, Tc85, SA85, GP82 y GP90. Estas no tienen actividad transialidasa ya que presentan mutaciones en los residuos de la región catalítica (la mutación más frecuente es Tyr342 por His342) (51,52). Sin embargo, son capaz de unirse a $\beta$-galactosa, laminina (53), fibronectina (54), colágeno $(44,55)$ y citoqueratina (56), y están involucradas en la adhesión e invasión a las células del huésped (54,57-59). Estas proteínas tienen motivos de Caja Asp completas o modificadas (SxDxGxTW); VTVxNVxLYNR es un motivo característico de todos los miembros de TS, y una secuencia de señal para la escisión/adición 
del anclaje GPI en la región C-terminal (37,57,60). ASP-1 y ASP-2 son proteínas de superficie del amastigote, mientras que TSA-1 es un antígeno de superficie de tripomastigote $(61,62)$. Las glucoproteínas SA85 se expresan en las formas amastigote y tripomastigote sanguíneo. Por último, la glicoproteína Tc85 se expresa densamente en tripomastigotes sanguíneos (45).

El grupo III está formado por proteínas de superficie presentes en tripomastigotes sanguíneos: CRP, FL160, CEA y TESA (63). Estas proteínas son reconocidas por sueros de pacientes con ECh y son capaces de inhibir la activación del complemento tanto por vía clásica como por vía alternativa (57,60,63-66), por lo cual representan un importante mecanismo de evasión del parásito. Las proteínas TESA son antígenos secretados/excretados de tripomastigotes y se distribuyen en toda la membrana celular de T. cruzi $(64,67)$ mientras que CRP, FL160 y CEA son proteínas de membranas asociadas al flagelo (68-70).

Por último, el grupo IV está compuesto por genes que codifican antígenos de superficie del tripomastigote cuya función biológica es aún desconocida. Este grupo está incluido en la superfamilia de la TS, ya que contiene el motivo conservado VTVxNVxLYNR, el cual es compartido por todos los miembros de TS $(35,45,46,71,72)$. El péptido B5 de la proteína TS-Tc13, un representante del grupo IV, es muy inmunogénico y está presente en la forma tripomastigote metacíclico (43).

Estos primeros cuatro grupos fueron descritos hace más de 20 años. Sin embargo, Freitas y colaboradores evidenciaron cuatro grupos más (V-VIII) en los cuales encontraron diferencias en las secuencias y observaron que los grupos V y VI están relacionados con el grupo II ya que son los únicos que no tienen un motivo llamado FRIP, mientras que las secuencias consenso del motivo VTVxNVxLYNR son muy similares. Por otra parte, los grupos VII y VIII estarían estrechamente relacionados con el grupo III, ya que ninguno presenta Caja Asp y tienen motivos similares (43). Recientemente se ha comprobado que una versión de este motivo (VTVTNVFLYNRPLN), denominado motivo FLY, puede actuar como factor de virulencia $(73,74)$. Además, FLY interactúa con las células endoteliales del corazón, lo que sugiere que podría contribuir al tropismo del parásito en este órgano (73). Este motivo FLY se ha reportado en miembros del grupo II y IV (43).

También se evidenció que el motivo FRIP (xRxP) se encuentra en el grupo I, III, IV, VII y VIII; y aunque está implicado en la unión del AcsS, se ha demostrado que los miembros enzimáticamente inactivos de la familia de las sialidasas en T. cruzi aún conservan las propiedades de unión a carbohidratos $(75,76)$.

\section{Rol de la Transialidasa en la invasión celular y la evasión del sistema inmune}

Para que un proceso infeccioso se pueda establecer, el agente causal, en este caso el parásito, debe ser capaz de evadir su detección temprana, es decir, impedir que la respuesta inmune del huésped sea capaz de eliminarlo (77).

La TS activa representa un importante factor de virulencia del parásito, ya que los niveles más altos de actividad enzimática se asocian con procesos tales como la penetración de la célula huésped o la patogénesis tisular (45). Se sabe que la TS, además de su rol clave en los mecanismos de invasión, tiene un papel muy importante en los mecanismos de evasión del sistema inmune (Figura 3B). Cuando el parásito ingresa al huésped, se encuentra en un entorno rico de células con AcsS, por lo que el parásito es capaz de cubrir su superficie de cargas negativas, a través de la reacción catalizada por la TS (Figura 3B-1). Esta capa actúa como una cubierta protectora para eludir los efectos de algunos compuestos séricos (78) (Figura 3B-2), y se observó que cuando dicha cubierta se elimina por tratamiento con sialidasa, los tripomastigotes son más susceptibles a la lisis mediada por el complemento (66). Además, en la superficie del parásito se encuentran sialilglicoconjugados como consecuencia de la actividad TS, los que permiten la unión a AcsS de lectinas de tipo Ig (Siglec-E) en las CDs, conduciendo a la supresión de la producción de IL-12 por parte de estas células, una citocina clave en la interconexión entre el sistema inmune innato y adaptativo (79) (Figura 3B-3).

Como se mencionó anteriormente, T. cruzi invade cualquier célula nucleada del huésped, tanto células fagocíticas (como los macrófagos) como no fagocíticas. Independientemente del mecanismo de penetración, la internalización del parásito conduce a la formación de una vacuola llamada vacuola parasitófora, cuya membrana interna se encuentra enriquecida de proteínas de membrana asociada a lisosomas (LAMP) altamente sialidadas (71,80,81). Esta vacuola posee pH ácido, lo cual favorece la transferencia de AcsS de las proteínas LAMP a la superficie del parásito, lo que genera una mayor susceptibilidad a la lisis de la vesícula mediada por Tc-Tox, una proteína derivada del parásito que forma poros en la membrana, permitiendo así que el parásito escape desde la misma hacia el citoplasma celular (81-84) (Figura 3B-4). 
Los mecanismos de evasión mediados por TSs también impactan sobre a la respuesta inmune adaptativa. Se considera que la región SAPA de la TS actúa como un señuelo distractor, ya que la presencia de epítopes Binmunodominantes en su estructura promueven la producción de anticuerpos no neutralizantes contra regiones distantes del sitio catalítico (48). Normalmente, en individuos infectados se detecta una respuesta robusta de anticuerpos contra la región $\mathrm{C}$ - terminal y $\mathrm{N}$ terminal de TS. Sin embargo, estudios pre-clínicos demostraron que los anticuerpos que reconocen el sitio catalítico de la TS, son capaces de conferir inmunidad pasiva a animales infectados, mientras que los anticuerpos dirigidos contra el dominio C-terminal no son protectores, ya que no logran bloquear la actividad enzimática (85). Así, es posible que el antígeno SAPA haya evolucionado para evitar la producción de anticuerpos protectores dirigidos contra la región catalítica N-terminal, esencial para la transferencia de AcsS. Por esta razón, la incorporación en formulaciones vacunales de TSs que carezcan del fragmento SAPA sería una estrategia prometedora para incrementar la producción de anticuerpos protectores $(86,87)$. La TS también puede activar en forma policlonal a los linfocitos B (88), y probablemente esto conduzca a restringir el tamaño del nicho requerido para un desarrollo óptimo de linfocitos específicos y protectores, al incrementar la competencia por señales de activación y supervivencia en los órganos linfoides $(89,90)$ (Figura 3B-5). Además, la superficie del tripomastigote es rica en a-galactosilmucinas, objetivos de los anticuerpos líticos (es decir anticuerpos que median reacciones de citotoxicidad). Sin embargo, T. cruzi evita la muerte inducida por estos anticuerpos debido a que logra repelerlos por tener una superficie cargada negativamente debido a la presencia de AcsS $(91,92)$ (Figura 3B-5).

Por otra parte, un estudio ha demostrado que la TS es capaz de activar los linfocitos T CD4, y de sialidar la superficie de los linfocitos T CD8 activados, lo cual limitaría su capacidad de inducir una respuesta efectora específica. Este mecanismo es también una importante estrategia de evasión parasitaria que influye indirectamente en la supervivencia de T. cruzi dentro de las células del huésped, ya que evita de esta manera el control inmunitario mediado por las células T CD8 (93) (Figura 3B-6).

Durante la infección por T. cruzi, la TS no solo se encuentra anclada en la superficie del parásito, sino que tras la escisión del GPI la TS es liberada en forma soluble al torrente sanguíneo. Esta última sería capaz de formar inmunocomplejos con anticuerpos específicos anti-TS, lo que provocaría un descenso en la concentración efectiva de anticuerpos neutralizantes circulantes (Figura 3B-7) $(94,95)$.

\section{Uso de Transialidasa como inmunógeno en formulaciones vacunales contra Trypanosoma cruzi}

Numerosos estudios pre-clínicos han centrado su interés en la utilización de miembros o derivados de la superfamilia de la TS para el desarrollo de distintas estrategias de profilaxis contra T. cruzi, los que se resumen en la Tabla 1 (96-100). Aquí nos centraremos en algunos de estos ensayos, y particularmente se mencionarán las estrategias utilizadas en los últimos años. 


\begin{tabular}{|c|c|c|c|c|c|}
\hline Antigeno & Adyuvante & Inmunización & Infección & Resultados & Referencia \\
\hline ADN TS & - & Intramuscular & $\begin{array}{l}\text { Intraperitoneal; Tripomastigotes } \\
\text { sanguineos }\end{array}$ & $\begin{array}{c}\uparrow \mathrm{lgG} 1, \uparrow \mid \mathrm{gG} 2 \mathrm{a}, \uparrow \mathrm{DHT} \uparrow \text { Proliferación } \\
\text { in vitro. } \\
\text { \parasitemia } \uparrow \text { supervivencia }\end{array}$ & $\begin{array}{l}\text { Fabio Costa, } \\
\text { et al. 1998 } \\
\text { (111) }\end{array}$ \\
\hline $\begin{array}{l}\text { Plásmidos con TS y/o TS } \\
\text { recombinante }\end{array}$ & -/óxido de aluminio & $\begin{array}{l}\text { intramuscular/ } \\
\text { intraperitoneal }\end{array}$ & $\begin{array}{l}\text { Intraperitoneal, Tripomastigotes } \\
\text { sanguíneos de la cepa Y }\end{array}$ & $\uparrow \lg \mathrm{G} 1, \uparrow \lg \mathrm{G} 2 \mathrm{a}, \uparrow \mathrm{INF}-\mathrm{y}$ in vitro & $\begin{array}{l}\text { José Ronnie } \\
\text { Vasconcelos, } \\
\text { et al. } 2003\end{array}$ \\
\hline Ad5+TS y/o Ad5+ASP-2 & - & Subcutánea & $\begin{array}{l}\text { Intraperitoneal; tripanosomas } \\
\text { sanguineos cepa } Y\end{array}$ & $\begin{array}{c}\uparrow \mid g G, \uparrow I N F-y \text { in vitro. } \\
\downarrow \text { parasitemia } \uparrow \text { supervivencia }\end{array}$ & $\begin{array}{l}\text { Alexandre V. } \\
\text { Machado, et } \\
\text { al. } 2006 \text { (113) }\end{array}$ \\
\hline TS recombinante & CpG ODN & $\begin{array}{l}\text { Intranasal e } \\
\text { intramuscular }\end{array}$ & $\begin{array}{l}\text { Oral, } T \text {. cruzi metacíclico derivado } \\
\text { de insecto }\end{array}$ & 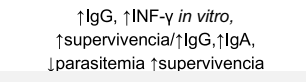 & $\begin{array}{l}\text { Daniel F. Hoft, } \\
\text { et al. 2007 } \\
\text { (107) }\end{array}$ \\
\hline TS recombinante & $\begin{array}{l}\text { Adyuvante de Freud } \\
\text { completo/incompleto }\end{array}$ & Subcutánea & $\begin{array}{l}\text { Intraperitoneal; Tripomastigotes } \\
\text { cepa Tulahuén }\end{array}$ & $\begin{array}{c}\uparrow \lg G, \downarrow \text { parasitemia, } \uparrow \text { supervivencia, } \\
\downarrow \text { daño tisular }\end{array}$ & $\begin{array}{l}\text { German H. } \\
\text { Fontanella, et } \\
\text { al. } 2008(87)\end{array}$ \\
\hline TS recombinante & $\begin{array}{l}\text { Oligonucleótidos con } \\
\text { motivos } \mathrm{CpG}\end{array}$ & Intranasal & $\begin{array}{l}\text { Ocular con Tripomastigotes } \\
\text { derivados de cultivo }\end{array}$ & $\begin{array}{l}\uparrow \operatorname{lgA}, \uparrow \text { Proliferación in vitro, } \uparrow \text { INF-y in } \\
\text { vitro, } \uparrow \text { supervivencia }\end{array}$ & $\begin{array}{l}\text { O. K. } \\
\text { Giddings, et }\end{array}$ \\
\hline Plásmido TS & Plásmido IL-15 & Intramuscular & $\begin{array}{l}\text { Tripomastigotes sanguineos cepa } \\
\text { Tulahuén }\end{array}$ & $\uparrow I N F-\gamma$ in vitro, $\uparrow$ supervivencia & $\begin{array}{l}\text { Christopher S. } \\
\text { Eickhoff } 2010 \\
\text { (85) }\end{array}$ \\
\hline $\begin{array}{c}\text { Mutante } \\
\text { glicosilada de TS inactiva } \\
\text { (TSm) }\end{array}$ & $\begin{array}{l}\text { ISCOMATRIX o } \\
\text { Adyuvante de Freud } \\
\text { completo }\end{array}$ & Subcutánea & $\begin{array}{l}\text { Intraperitoneal; Tripomastigotes } \\
\text { sanguineos cepa Tulahuén }\end{array}$ & $\begin{array}{c}\uparrow l g G 1, \uparrow \operatorname{lgG2a}, \uparrow \mathrm{DHT}, \uparrow \mathrm{INF}-\mathrm{y} \text { e IL-10 } \\
\text { in vitro, } \downarrow \text { parasitemia, } \uparrow \text { supervivencia, } \\
\downarrow \text { carga parasitaria tisular }\end{array}$ & $\begin{array}{l}\text { Iván Alejandro } \\
\text { Bontempi, et } \\
\text { al. } 2015 \text { (86) }\end{array}$ \\
\hline Trasapaína & di-AMP-c & Intranasal & $\begin{array}{l}\text { Intraperitoneal; Tripomastigotes } \\
\text { sanguineos cepa RA }\end{array}$ & $\begin{array}{c}\uparrow l g G 1, \uparrow D H T, \uparrow \text { Proliferación in vitro. } \\
\uparrow \mid N F-y, \text { TNF-a, IL-2, IL-4 in vitro } \\
\text { \parasitemia } \uparrow \text { supervivencia, } \downarrow \text { daño } \\
\text { tisular/ Th17, } \downarrow \text { carga parasitaria e } \\
\text { inflamación crónica }\end{array}$ & $\begin{array}{l}\text { Andrés } \\
\text { Sanchez } \\
\text { Alberti, et al. } \\
2017(110)\end{array}$ \\
\hline TSf & $\begin{array}{l}\text { ISPA (Partículas } \\
\text { inmunoestimulantes) }\end{array}$ & Subcutánea & $\begin{array}{l}\text { Intraperitoneal; Tripomastigotes } \\
\text { sanguineos cepa Tulahuén }\end{array}$ & $\begin{array}{c}\uparrow \lg \mathrm{G} 1, \uparrow \operatorname{lgG} 2 \mathrm{a}, \uparrow \mathrm{DHT} \uparrow \mathrm{INF}-\mathrm{y} \text { in vitro } \\
\downarrow \text { parasitemia } \uparrow \text { supervivencia }\end{array}$ & $\begin{array}{l}\text { Estefania } \\
\text { Prochetto, et } \\
\text { al. } 2017 \text { (108) }\end{array}$ \\
\hline $\begin{array}{c}\text { L. lactis TS } \\
\text { L. lactis TS+di-AMP-c }\end{array}$ & L. lactis di-AMP-c & Oral & - & $\uparrow \mathrm{DHT}$ & $\begin{array}{l}\text { Ingrid } \\
\text { Quintana, et } \\
\text { al. } 2018(32)\end{array}$ \\
\hline $\begin{array}{l}\text { Salmonella enterica } \\
\text { serovar Typhimurium } \\
\text { aroA } 7207 \text { (SaroA) + } \\
\text { plásmido Traspaina }\end{array}$ & di-AMP-c/CpG & $\begin{array}{l}\text { Dos dosis orales de } \\
\text { SaroA + dos dosis } \\
\text { nasales de Trapaina }\end{array}$ & $\begin{array}{l}\text { Intraperitoneal; Tripomastigotes } \\
\text { sanguineos cepa RA }\end{array}$ & $\begin{array}{c}\uparrow \operatorname{lgG} 1, \uparrow \mathrm{DHT}, \uparrow \text { Proliferación in vitro. } \\
\uparrow \text { INF-y, IL-17, IL-2, IL-4 in vitro, } \\
\downarrow \text { parasitemia } \uparrow \text { supervivencia, } \downarrow \text { daño } \\
\text { tisular }\end{array}$ & $\begin{array}{l}\text { Andrés } \\
\text { Sanchez } \\
\text { Alberti, et al. } \\
2020(114)\end{array}$ \\
\hline
\end{tabular}

Tabla 1. Estudios sobre vacunas profilácticas contra Trypanosoma cruzi realizadas a lo largo de los años basadas en Transialidasa. Tabla resumen sobre el uso de Transialidasa en diversas estrategias vacunales desarrolladas a lo largo de los años. Aquí se detalla el antígeno y adyuvante de la formulación, la vía de administración, los resultados observados y las referencias correspondientes. Dentro de los resultados se puede observar el incremento $(\uparrow)$ o la disminución ( $\downarrow$ ) de los parámetros estudiados como resultado del diagrama experimental empleado.

En una primera instancia, se utilizaron en las formulaciones vacunales formas enzimáticamente activas de la TS. Sin embargo, se demostró más tarde que la utilización de las formas activas genera en ratones una serie de efectos adversos tales como toxicidad hepática y alteraciones a nivel del miocardio y del bazo (101,102), sin cambios significativos en la tasa de protección (101), razón por la cual se consideró que este tipo de formulaciones no eran lo suficientemente seguras como para ser probadas en humanos (103).

A partir de estos resultados, se tendió a utilizar miembros inactivos de la familia de la TS. Aquí comenzaron a jugar otros aspectos que podrían influir negativamente en el proceso de inmunización, tales como la expresión diferencial de los mismos en las distintas etapas de la vida del parásito o la posibilidad de inducir anergia en la respuesta inmune $(59,87,104)$. En función de esto, las estrategias más prometedoras fueron el uso de mutantes inactivos de las TS del grupo I, o bien fragmentos recombinantes inactivos que no incluyeran la región SAPA (87), debido a que la utilización de estos inmunógenos aseguraría el mantenimiento de la inmunogenicidad y disminuiría la posibilidad de presentar reacciones adversas. Diversos estudios pre-clínicos han utilizado estas estrategias, tal como se describe a continuación.

\section{Proteínas recombinantes derivadas de Transialidasa}

En la era de la ingeniería genética, surgieron las vacunas basadas en proteínas recombinantes. La vacuna contra la hepatitis B fue la primera vacuna autorizada para su uso en humanos producida en base a esta tecnología. Estas vacunas están formadas por fragmentos del antígeno que son altamente inmunogénicos. Una ventaja de este tipo de vacunas es que son seguras (no inducen infección) y su probabilidad de inducir reacciones adversas severas es potencialmente menor (105). Sin embargo, este tipo de vacunas requieren de adyuvantes para lograr una respuesta inmunitaria protectora (106).

En este contexto y durante el año 2007, un estudio pre-clínico probó una proteína recombinante derivada de TS (TSr) junto al adyuvante CpG (agonista del TLR—9). Esta TSr presenta una mutación 
puntual en el aminoácido 342 que provoca un cambio de histidina por tirosina, lo cual conduce a la pérdida de la actividad catalítica. Esta TSr fue administrada tanto de forma intramuscular como intranasal (dos dosis separadas por 15 días en cada uno de los casos). Ambos esquemas de inmunización proporcionaron un buen nivel de protección. La administración intramuscular proporcionó buenos niveles séricos de IgG específica, indujo un perfil Thl (caracterizado por la secreción de INF- $-\gamma$ ), e incrementó la supervivencia de los animales. A nivel nasal, su administración indujo niveles elevados de inmunoglobulinas específicas (IgG sérica e IgA en extractos fecales), controló la parasitemia y logró una mayor activación de células T CD4 y CD8 (107).

En otro estudio donde también se administró TS+CpG por vía intranasal, se observó un sesgo hacia Thl y una respuesta de linfocitos T CD8 específica dirigida contra el epitope inmunodominante IYNVGQVSI. Esta inmunización también provocó el desarrollo de inmunidad humoral específica en mucosas, a juzgar por la aparición de IgA anti-TSr en heces y lágrimas. Posteriormente, el desafío fue realizado tanto con tripomastigotes metacíclicos como sanguíneos, los que fueron inoculados de forma subcutánea o en la mucosa conjuntiva. Independientemente del esquema utilizado de infección, los animales que habían sido previamente inmunizados con TS+CpG mostraron una mayor tasa de supervivencia (85).

Investigadores de nuestro instituto llevaron a cabo un estudio pre-clínico en donde se administró una TSr glicosilada que poseía una mutación en el sitio activo (TSm) y que carecía las repeticiones inmunodominantes SAPA, emulsionada en adyuvante de Freund. En los animales inmunizados se observaron títulos elevados de anticuerpos específicos y esto se acompañó de una mayor tasa de supervivencia, asociada a la falta de evidencia clínica o tisular de infección en comparación con los ratones no vacunados e infectados (87). Unos años más tarde, Bontempi y col., utilizaron la TSm junto al inmunopotenciador ISCOMATRIX en un esquema de 3 dosis. Esta formulación indujo a nivel sistémico la aparición de IgG2a contra TS. La respuesta celular hacia la TSm se evidenció por la positividad de las pruebas de hipersensibilidad retardada (DHT), la secreción equilibrada de IFN $-\gamma$ e IL-10 por esplenocitos desafiados in vitro con TS y una fuerte producción de IFN $-\gamma$ en linfocitos T CD8. El grado de efectividad de la vacuna fue alto, ya que un alto porcentaje de los animales que recibieron TSm+ISCOMATRIX sobrevivieron, mientras que el resto presentó una elevada mortalidad. Esta formulación vacunal logró un mejor control de la carga parasitaria tisular no sólo durante la etapa aguda sino también durante la crónica (100 días post-infección). A nivel cardíaco, también indujo una disminución del infiltrado inflamatorio y menor grado de lesiones (86).

Más recientemente, se evaluó un nuevo inmunógeno derivado de TS, que consistía en un fragmento de tamaño reducido (TSf) expresado en E. coli, junto a un adyuvante similar al ISCOMATRIX llamado ISPA. En términos de inmunogenicidad, esta formulación generó un sesgo hacia el perfil Thl caracterizado por un incremento en la relación IgG2a/IgGl con presencia de anticuerpos líticos, una evidente reactividad celular específica, como también una mayor producción de IFN- $\gamma$ por los linfocitos T CD8 esplénicos. En cuanto a la eficacia, esta formulación vacunal logró disminuir significativamente la parasitemia. En parte, la importancia de este estudio radica en el hecho que, si bien ya previamente se había demostrado que la inmunización con una TSr de longitud completa logra buenos niveles de protección, disponer de una TSr de tamaño reducido con capacidad protectora como la TSf, representa una herramienta valiosa para facilitar el desarrollo de una vacuna, teniendo en cuenta que la expresión heteróloga de antígenos mejora cuando el tamaño de la secuencia de ADN es inferior a 1000 pares de bases (108).

En un trabajo realizado recientemente, se evaluó la administración nasal de Traspaína, un ingenioso antígeno quimérico trivalente que conjuga el dominio $\mathrm{N}$-terminal de la $\mathrm{Cz}$, la región central de ASP2 y una porción de una TS inactiva (iTS), formulada junto al adyuvante diAMPc (109). La administración de la quimera adyuvada con el nucleótido dicíclico condujo a un elevado nivel de anticuerpos IgG específicos con capacidad neutralizante. En cuanto a la respuesta celular, se observó un incremento en el nivel de citocinas con un perfil compatible con Th1/Th17 tras la re-estimulación in vitro con el antígeno. Incluso se observó el desarrollo de linfocitos T CD8 con capacidad citotóxica dirigidos contra el epítope inmunodominante de ASP2. La efectividad vacunal de la formulación Traspaína+diAMPc fue elevada, ya que los ratones inmunizados evidenciaron un menor score clínico durante la infección y lograron controlar las lesiones tisulares clásicas de la fase crónica (110). 


\section{Transialidasa en vacunas de ADN}

Las vacunas de $\mathrm{ADN}$ consisten en una secuencia de este ácido nucleico, que codifica para el antígeno de interés. Tras ser captado por las células del individuo vacunado, el ADN se copiará a ARN y luego se traducirá a proteína, la que estimulará de forma artificial al sistema inmune. Estas vacunas son simples de producir, relativamente económicas y estables, lo cual facilita su producción a gran escala $(105,106)$. Diversas vacunas de ADN se encuentran en fase pre-clínica y clínica, y hasta el momento ninguna ha sido aprobada para su uso en humanos. Sin embargo, la gran cantidad de estudios que evalúan vacunas de ADN en relación a la COVID19, sugieren que podrían ser a corto plazo ampliamente utilizadas contra diversos patógenos, al igual que las vacunas de ARN, que se basan en una tecnología similar.

Los primeros estudios pre-clínicos que utilizaron esta estrategia consistieron en la administración de un ADN plasmídico que codificaba un fragmento del dominio catalítico de la TS. Los ensayos de inmunogenicidad comprobaron que esta vacuna inducía tanto una respuesta humoral (mayoritariamente IgGl) como celular específica (mediante DHT). Incluso, los anticuerpos presentes en el suero mostraron capacidad neutralizante, ya que podían reconocer in vitro a la enzima nativa e inhibir su actividad. Finalmente, los estudios de protección demostraron una reducción significativa en la parasitemia y la mortalidad (111).

Posteriormente se evaluó si la inmunización combinada con ADN y TSr (ambas estrategias basadas en la región catalítica de TS), otorgaba mejores resultados en términos de inmunogenicidad y eficacia vacunal. Los resultados de estos estudios mostraron que los animales inmunizados exclusivamente con el plásmido p154/13-TS desarrollaron una respuesta inmune predominantemente Thl, mientras que, la inmunización con TSr emulsionada en óxido de aluminio (Al2O3) generó un perfil de respuesta Th2. La administración simultánea de ambos inmunógenos también favoreció el desarrollo de un perfil Th2. Posteriormente se evaluó una estrategia de "prime-boost", la cual consistió en la administración secuencial de los inmunógenos: dos dosis con el plásmido p154/13 - TS seguida de dos dosis de TSr, tras lo cual se observó el desarrollo de un perfil Thl. Sin embargo, los ensayos de protección que utilizaban esta estrategia "prime-boost" mostraron una eficacia relativamente baja (112).

Utilizando nuevamente el plásmido p154/13-TS (aquí llamado pTS), Eickhoff y col. evaluaron su efectividad cuando era co—adyuvado por IL-15 (pIL-15), citocina que promueve la supervivencia de los linfocitos $\mathrm{T}$ de memoria. Los resultados mostraron que pTS generó buenos niveles de protección, independientemente si era o no co-adyuvada por pIL-15 cuando el desafío con T. cruzi se realizó un mes post-inmunización. Sin embargo, cuando los animales se infectaron 6 meses post-inmunización, solo aquellos que habían recibido también pIL-15 mostraron buenos niveles de protección (99), lo cual demostraba efectivamente la necesidad de contar con IL—15 para generar memoria a largo plazo.

El sistema de entrega o "delivery" del ADN que se utilice en este tipo de vacunas es también un factor muy importante a la hora de su diseño. El ADN se puede vehiculizar dentro de las células del hospedero en forma desnuda ("naked DNA"), mediante un plásmido como se mencionó anteriormente, o bien utilizando un vector viral o bacteriano. Los adenovirus son uno de los vectores más utilizados en el diseño de vacunas, ya que, entre otras propiedades, tienen la capacidad de inducir una respuesta celular de tipo Thl. En un trabajo realizado por Machado y col., se evaluó el uso combinado de dos Ad5 modificados genéticamente que codificaban fragmentos de TS o ASP-2. Los estudios de inmunogenicidad reportaron niveles elevados de anticuerpos específicos, un sesgo hacia el perfil Thl y una respuesta de linfocitos T citotóxicos sustancial. La efectividad vacunal de esta formulación fue elevada, ya que logró muy buenos niveles de protección. Además, se demostró que la protección era dependiente de linfocitos T CD8, ya que cuando la inmunización se realizó en ratones deficientes en este tipo celular, se presentó un fallo en la inmunidad protectora. Estos resultados sugieren que los Ad5 podrían ser una buena opción para el desarrollo de una vacuna contra T. cruzi (113).

Una estrategia de "prime-boost" prometedora consistió en la administración de dos dosis de un vector bacteriano (Salmonella enterica serovar Typhimurium aroA 7207) que transportaba el plásmido que codificaba para el antígeno quimérico Traspaína, seguida de dos refuerzos de la quimera recombinante emulsionada en di-AMP—c. Este esquema vacunal logró una fuerte reducción de los parásitos en sangre, una respuesta celular específica sesgada al perfil Thl/Thl7, y una reducción del daño cardíaco (114).

Por otra parte, recientemente nuestro grupo utilizó bacterias L. lactis modificadas genéticamente como un sistema dual de "delivery" y de expresión. Estas bacterias recombinantes co-producen un fragmento C-terminal de la TS (TScf) y el adyuvante diAMPc. Los estudios pre-clínicos de 
inmunogenicidad demostraron que la administración oral de esta formulación induce una fuerte respuesta celular específica (por DHT) e inmunidad humoral sistémica. Este tipo de sistema vacunal podría representar una plataforma simple, económica y sin riesgos respecto a su seguridad, ya que emplea una bacteria no patogénica habitualmente utilizada en la industria alimenticia (32).

\section{Consideraciones finales}

Desde el descubrimiento de la ECh en 1909 por Carlos Chagas hasta la actualidad se han evaluado diferentes vacunas a nivel pre-clínico para evitar esta enfermedad, sin embargo, aún no se ha logrado el desarrollo de una vacuna efectiva contra el parásito $(115,116)$. Uno de los principales impedimentos ha sido el hecho que con ninguna de las vacunas evaluadas se ha logrado inmunidad esterilizante.

Si bien en estas últimas décadas se han desarrollado distintas plataformas que permiten el diseño de vacunas más seguras, estas requieren generalmente de adyuvantes y de un mayor número de dosis para conferir memoria a largo plazo. Por otra parte, si bien la mayoría de las vacunas confieren protección a través de anticuerpos neutralizantes, cada vez es más evidente que para ciertos patógenos de vida intracelular es además imprescindible generar una adecuada respuesta celular, preferentemente Thl (117). En el contexto del desarrollo de una vacuna para prevenir la ECh, los candidatos vacunales deben ser moléculas cruciales para el patógeno y altamente inmunogénicas; expresarse en las formas presentes en el hospedero mamífero (amastigote y tripomastigote); estar conservadas y, de ser posible, que junto al adyuvante induzcan respuestas humorales acompañadas de una respuesta Thl/Th17 $(110,115)$. Por otra parte, la inmunización mucosal presenta una serie de ventajas comparada con la ruta parenteral, dentro de las cuales se puede mencionar que la administración es fácil e indolora, presenta bajo riesgo de contaminación cruzada y de efectos secundarios, no requiere de personal capacitado para su aplicación y es una vía que presenta buena aceptación por el público (118). El hecho que T. cruzi utilice como punto de entrada algunas mucosas (como la conjuntival, bucal y gastrointestinal), sugiere que la administración de antígenos a nivel mucosal podría representar la estrategia ideal de inmunización, debido a la posibilidad de inducir protección no sólo a nivel local sino también a nivel sistémico. Esta vía de inmunización está comenzando a ser evaluada en mayor profundidad, junto a una nueva generación de adyuvantes específicos de mucosa, con resultados promisorios.

En la presente revisión realizamos un recorrido a través de distintas estrategias de inmunización profiláctica que se han evaluado a nivel pre-clínico utilizando particularmente la enzima TS o sus fragmentos como antígeno vacunal. Cabe remarcar que, dado que actualmente se acepta que el daño tisular depende en parte de la persistencia del parásito, se ha comenzado a evaluar el posible uso de vacunas terapéuticas, a fin de minimizar la carga del agente infeccioso una vez que la Ech se ha establecido. Esto permitiría evitar o reducir las comorbilidades propias de la fase crónica de esta enfermedad y prolongar la vida de los pacientes (119). Asimismo, este tipo de vacunas presentaría ciertas ventajas, tales como tasas más elevadas de seroconversión, e incluso podrían potencialmente utilizarse en embarazas para prevenir el Chagas congénito (120).

Es evidente que las estrategias vacunales que se han abordado a lo largo de más de 100 años han sido muy diversas, se han ido perfeccionado y los resultados obtenidos hasta el momento podrían llevarse al campo clínico en un futuro cercano.

Fuente de financiamiento: ANCYPT (PICT 2016-0312; PICT 2018-01893), SECYT-UNR (1MED516).

Agradecimientos: Agradecemos al Dr. Ivan Marcipar por la lectura crítica y constructiva del manuscrito.

\section{Referencias bibliográficas}

1. PAHO. Chagas disease - PAHO/WHO | Pan American Health Organization. 2018.

2. Buscaglia CA, Di Noia JM. Trypanosoma cruzi clonal diversity and the epidemiology of Chagas' disease. Microbes and Infection. Elsevier Masson SAS; 2003;5(5):419-27.

3. WHO Expert Committee. Control of Chagas Disease. World Health Organ Tech Rep Ser. 2002;905:1-109.

4. Bonney KM, Luthringer DJ, Kim SA, Garg NJ, Engman DM. Pathology and Pathogenesis of Chagas Heart Disease. Annu Rev Pathol Mech Dis. 2019 Jan 24;14(1):421-47. 
5. Shikanai-Yasuda Maria Aparecida, Carvalho Noemia Barbosa. Oral Transmission of Chagas Disease. Clin Infect Dis | Oxford Acad. 2012;54(6):845-52.

6. Brener Z. Life cycle of Trypanosoma cruzi. Rev Inst Med Trop Sao Paulo. 1971;13(3):171-8.

7. Mandal S. Epidemiological Aspects of Chagas Disease - a Review. 2014;2(2):117.

8. Bern C. Chagas' disease. Longo DL, editor., New England Journal of Medicine. Massachussetts Medical Society. 2015;373:456-66.

9. Tanowitz HB, Machado FS, Spray DC, Friedman JM, Weiss OS, Lora JN, et al. Developments in the management of Chagas cardiomyopathy. Expert Review of Cardiovascular Therapy. Taylor and Francis Ltd. 2015;13(12):1393-409.

10. Hasslocher-Moreno Alejandro M, do Brasil Pedro E A A, de Sousa Andrea S, Xavier Sergio S, Chambela Mayara C, Sperandio da Silva Gilberto M. Safety of Benznidazole Use in the Treatment of Chronic Chagas' Disease. J Antimicrob Chemother. 2012;67(5):1261-6.

11. Rassi A, Dias JCP, Marin - Neto JA, Rassi A. Challenges and opportunities for primary, secondary, and tertiary prevention of Chagas' disease. Heart. Heart. 2009;95:524-34.

12. Junqueira C, Caetano B, Bartholomeu DC, Melo MB, Ropert C, Rodrigues MM, et al. The endless race between Trypanosoma cruzi and host immunity: Lessons for and beyond Chagas disease. Expert Reviews in Molecular Medicine. Expert Rev Mol Med. 2010;12: e29.

13. Romero—Dávalos A. Enfermedad de Chagas. La Paz, Bolivia: Los Amigos del Libro; 1979;115-150.

14. Basso B, Marini V. Experimental Chagas disease in Balb/c mice previously vaccinated with T. rangeli: II: The innate immune response shows immunological memory: Reality or fiction? Immunobiology. 2015 Mar 1;220(3):428-36.

15. Breganó JW, Picão RC, Graça VK, Menolli RA, Jankevicius SI, Filho PP, et al. Phytomonas serpens, a tomato parasite, shares antigens with Trypanosoma cruzi that are recognized by human sera and induce protective immunity in mice. FEMS Immunol Med Microbiol. 2003;39(3):257-64.

16. Ruiz AM, Esteva M, Cabeza Meckert P, Laguens RP, Segura EL. Protective immunity and pathology induced by inoculation of micewith different subcellular fractions of Trypanosoma cruzi. Acta Trop. 1985;42(4):299-309.

17. Snary D. Cell surface glycoproteins of Trypanosoma cruzi: protective immunity in mice and antibody levels in human chagasic sera. Trans R Soc Trop Med Hyg. 1983;77(1):126-9.

18. Araujo FG, Morein B. Immunization with Trypanosoma cruzi Epimastigote Antigens Incorporated into Iscoms Protects against Lethal Challenge in Mice. INFECTION AND IMMUNITY. 1991;59(9):2909-2914.

19. Gomes YM, Abath FGC, Nakazawa M, Minoprio P, Vouldoukis I, Monjour L. Partial Protection of Mice against Trypanosoma cruzi after Immunizing with the TcY 72 Antigenic Preparation. Mem Inst Oswaldo Cruz. 1999;94(2):167-72.

20. El-Sayed NM, Myler PJ, Bartholomeu DC, Nilsson D, Aggarwal G, Tran A-N, et al. The genome sequence of Trypanosoma cruzi, etiologic agent of Chagas disease. Science. 2005;309(5733):409-15.

21. Norris KA, Galvao LMC, Schrimpf JE, Cancado JR, Krettli AU. Humoral immune response to the Trypanosoma cruzi complement regulatory protein as an indicator of parasitologic clearance in human Chagas' disease. Infect Immun. 1994;62(9):4072-4.

22. Fonseca SG, Moins-Teisserenc H, Clave E, Ianni B, Nunes VL, Mady C, et al. Identification of multiple HLA-A*0201—restricted cruzipain and FL-160 CD8+ epitopes recognized by T cells from chronically Trypanosoma cruzi-infected patients. Microbes Infect. 2005;7(4):688-97.

23. Krautz GM, Peterson JD, Godsel LM, Krettli AU, Engman DM. Human antibody responses to Trypanosoma cruzi 70—kD heat—shock proteins. Am J Trop Med Hyg. 1998;58(2):137-43.

24. Godsel LM, Engman DM. Flagellar protein localization mediated by a calcium—myristoyl/palmitoyl switch mechanism. EMBO J. 1999;18(8):2057-65.

25. Yoshida N, Araya JE, da Silveira JF, Giorgio S. Trypanosoma cruzi: Antibody production and T cell response induced by stage—specific surface glycoproteins purified from metacyclic trypomastigotes. Exp Parasitol. 1993;77(4):405-13.

26. Fernandez-Gomez R, Esteban S, Gomez-Corvera R, Zoulika K, Ouaissi A. Trypanosoma cruzi: Tc52 released protein-induced increased expression of nitric oxide synthase and nitric oxide production by macrophages. J Immunol. 1998;160(7):3471-9.

27. Pereira VRA, Lorena VMB, Verçosa AFA, Silva ED, Ferreira AGP, Montarroyos UR, et al. Antibody Isotype Responses in Balb/c Mice Immunized with the Cytoplasmic Repetitive Antigen and Flagellar Repetitive Antigen of Trypanosoma cruzi. Mem Inst Oswaldo Cruz. 2003;98(6):823-5.

28. Matos MN, Cazorla SI, Schulze K, Ebensen T, Guzmán CA, Malchiodi EL. Immunization with Tc52 or its amino terminal domain adjuvanted with c-di-AMP induces Thl7+Thl specific immune responses and confers protection against Trypanosoma cruzi. PLoS Negl Trop Dis. 2017;11(2):e0005300.

29. García GA, Arnaiz MR, Laucella SA, Esteva MI, Ainciart N, Riarte A, et al. Immunological and pathological responses in BALB/c mice induced by genetic administration of Tc13 Tul antigen of Trypanosoma cruzi. Parasitology. 2006;132(6):855-66.

30. Cazarla SI, Frank FM, Becker PD, Arnaiz M, Mirkin GA, Corral RS, et al. Redirection of the immune response to the functional catalytic domain of the cystein proteinase cruzipain improves protective immunity against trypanosoma cruzi infection. J Infect Dis. 2010;202(1):136-44 .

31. Barbosa RPA, Filho BG, Santos LI dos, Junior PAS, Marques PE, Pereira RVS, et al. Vaccination Using Recombinants Influenza and Adenoviruses Encoding Amastigote Surface Protein—2 Are Highly Effective on Protection against Trypanosoma cruzi Infection. PLoS One. 2013;8(4):e61795.

32. Quintana I, Espariz M, Villar SR, González FB, Pacini MF, Cabrera G, et al. Genetic Engineering of Lactococcus lactis Co—producing Antigen and the Mucosal Adjuvant 3' 5'-cyclic di Adenosine Monophosphate (c-di-AMP) as a Design Strategy to Develop a Mucosal Vaccine Prototype. Front Microbiol. 2018;9(SEP):2100.

33. Rappuoli R. Reverse vaccinology Rino Rappuoli. Curr Opin Microbiol. 2000;2000(3):445-450.

34. Bhatia V, Sinha M, Luxon B, Garg N. Utility of the Trypanosoma cruzi sequence database for identification of potential vaccine candidates by in silico and in vitro screening. Infect Immun. 2004;72(11):6245-6254

35. Freire-De-Lima L, Fonseca LM, Oeltmann T, Mendoncą-Previato L, Previato JO. The trans-sialidase, the major Trypanosoma cruzi virulence factor: Three decades of studies. Glycobiology. 2015;25:1142-9. 
36. Previato J, Andrade AFB, Pessolani MC V., Mendonça-Previato L. Incorporation of sialic acid into Trypanosoma cruzi macromolecules. A proposal for a new metabolic route. Mol Biochem Parasitol. 1985;16(1):85-96.

37. Frasch ACC. Functional diversity in the trans-sialidase and mucin families in Trypanosoma cruzi. Parasitology Today. Parasitol Today; 2000;16(7):282-6.

38. Atwood JA, Weatherly DB, Minning TA, Bundy B, Cavola C, Opperdoes FR, et al. Microbiology: The Trypanosoma cruzi proteome. Science (80-). 2005;309(5733):473-6.

39. Frevert U, Schenkman S, Nussenzweig V. Stage-specific expression and intracellular shedding of the cell surface trans-sialidase of Trypanosoma cruzi. Infect Immun. 1992;60(6):2349-2360.

40. Lantos AB, Carlevaro G, Araoz B, Ruiz Diaz P, Camara MdlM, Buscaglia CA, et al. Sialic Acid Glycobiology Unveils Trypanosoma cruzi Trypomastigote Membrane Physiology. PLoS Pathog. 2016;12(4):e1005559.

41. Gaskell A, Crennell S, Taylor G. The three domains of a bacterial sialidase: a $\beta$-propeller, an immunoglobulin module and a galactose-binding jelly—roll. Structure. 1995;3(11):1197-1205.

42. Copley RR, Russell RB, Ponting CP. Sialidase-like Asp-boxes: Sequence-similar structures within different protein folds. Protein Sci. 2001;10(2):285-92

43. Freitas LM, dos Santos SL, Rodrigues—Luiz GF, Mendes TAO, Rodrigues TS, Gazzinelli RT, et al. Genomic analyses, gene expression and antigenic profile of the trans-sialidase superfamily of trypanosoma cruzi reveal an undetected level of complexity. PLoS One. 2011;6(10):25914.

44. Velge P, Ouaissi M A, Cornette J, Afchain D, Capron A. Identification and isolation of Trypanosoma cruzi trypomastigote collagen-binding proteins: Possible role in cell—parasite interaction. Parasitology. 1988;97(2):255-68.

45. Cross GAM, Takle GB. The Surface Trans-Sialidase Family of Trypanosoma Cruzi. Annu Rev Microbiol. 1993;47(1):385-411.

46. Schenkman S, Eichinger D, Pereira MEA, Nussenzweig V. Structural and Functional Properties of Trypanosoma Trans-Sialidase. Annu Rev Microbiol. 1994;48(1):499-523.

47. Schenkman S, De Carvalho LP, Nussenzweig V. Trypanosoma cruzi trans—sialidase and neuraminidase activities can be mediated by the same enzymes. J Exp Med. 1992;175(2):567-575.

48. Buscaglia CA, Alfonso J, Campetella O, Frasch ACC. Tandem amino acid repeats from Trypanosoma cruzi shed antigens increase the half-life of proteins in blood. Blood. 1999;93(6):2025-32.

49. Zingales B, Carniol C, de Lederkremer RM, Colli W. Direct sialic acid transfer from a protein donor to glycolipids of trypomastigote forms of Trypanosoma cruzi. Mol Biochem Parasitol. 1987;26(1-2):135-44.

50. Briones MRS, Egima CM, Schenkman S. Trypanosoma cruzi trans—-sialidase gene lacking C—terminal repeats and expressed in epimastigote forms. Mol Biochem Parasitol. 1995;70(1-2):9-17.

51. Uemura H, Schenkman S, Nussenzweig V, Eichinger D. Only some members of a gene family in Trypanosoma cruzi encode proteins that express both trans-sialidase and neuraminidase activities. EMBO J. 1992;11(11):3837-44.

52. 52. Cremona ML, Sánchez DO, Frasch ACC, Campetella O. A single tyrosine differentiates active and inactive Trypanosoma cruzi transsialidases. Gene. 1995;160(1):123-8.

53. Giordano R, Chammas R, Veiga SS, Colli W, Alves MJ. Trypanosoma cruzi binds to laminin in a carbohydrate-independent way. Braz J Med Biol Res. 1994;27(9):2315-8.

54. Ouaissi A, Cornette J, Taibi A, Velge P, Capron A. Major surface immunogens of Trypanosoma cruzi trypomastigotes. Mem Inst Oswaldo Cruz. 1988;83(1):502.

55. Santana JM, Grellier P, Schrével J, Teixeira ARL. A Trypanosoma cruzi-secreted 80 kDa proteinase with specificity for human collagen types I and IV. Biochem J. 1997;325(Pt 1):129-37.

56. Magdesian MH, Giordano R, Ulrich H, Juliano MA, Juliano L, Schumacher RI, et al. Infection by Trypanosoma cruzi: Identification of a parasite ligand and its host cell receptor. J Biol Chem. 2001;276(22):19382-9.

57. Colli W. Trans -sialidase: a unique enzyme activity discovered in the protozoan Trypanosoma cruzi. FASEB J. 1993;7(13):1257-64.

58. Claser C, Espíndola NM, Sasso G, Vaz AJ, Boscardin SB, Rodrigues MM. Immunologically relevant strain polymorphism in the Amastigote Surface Protein 2 of Trypanosoma cruzi. Microbes Infect. 2007;9(8):1011-9.

59. Colli W, Alves MJM. Relevant Glycoconjugates on the Surface of Trypanosoma cruzi. Mem Inst Oswaldo Cruz. 1999;94(1):37-49.

60. Campetella O, Sánchez D, Cazzulo JJ, Frasch ACC. A superfamily of trypanosoma cruzi surface antigens. Parasitol Today. 1992;8(11):378-81.

61. Low HP, Tarleton RL. Molecular cloning of the gene encoding the $83 \mathrm{kDa}$ amastigote surface protein and its identification as a member of the Trypanosoma cruzi sialidase superfamily. Mol Biochem Parasitol. 1997;88(1-2):137-49.

62. Santos MA., Garg N, Tarleton RL. The identification and molecular characterization of Trypanosoma cruzi amastigote surface protein-1, a member of the trans—sialidase gene super—family. Ac. Mol Biochem Parasitol. 1997;86(1):1-11.

63. Correa PRC, Cordero EM, Gentil LG, Bayer-Santos E, Silveira JF Da. Genetic structure and expression of the surface glycoprotein GP82, the main adhesin of Trypanosoma cruzi metacyclic trypomastigotes. The Scientific World Journal. 2013;2013:156734.

64. Matsumoto TK, Cotrim PC, Da Silveira JF, Stolf AMS, Umezawa ES. Trypanosoma cruzi: Isolation of an immunodominant peptide of TESA (trypomastigote excreted—secreted antigens) by gene cloning. Diagn Microbiol Infect Dis. 2002;42(3):187-92.

65. Beucher M, Norris KA. Sequence diversity of the Trypanosoma cruzi complement regulatory protein family. Infect Immun. 2008;76(2):750-8.

66. Kipnis TL, David JR, Alper CA, Sher A, da Silva WD. Enzymatic treatment transforms trypomastigotes of Trypanosoma cruzi into activators of alternative complement pathway and potentiates their uptake by macrophages. Proc Natl Acad Sci U S A. 1981;78(1):602-5. 
67. Berrizbeitia M, Ndao M, Bubis J, Gottschalk M, Aché A, Lacouture S, et al. Purified excreted—secreted antigens from trypanosoma cruzi trypomastigotes as tools for diagnosis of Chagas' disease. J Clin Microbiol. 2006;44(2):291-6.

68. Cetron MS, Hoff R, Kahn S, Eisen H, Van Voorhis WC. Evaluation of recombinant trypomastigote surface antigens of Trypanosoma cruzi in screening sera from a population in rural Northeastern Brazil endemic for chagas' disease. Acta Trop. 1992; 50(3):259—266.

69. Norris KA, Schrimpf JE, Szabo MJ. Identification of the gene family encoding the 160-kilodalton Trypanosoma cruzi complement regulatory protein. Infect Immun. 1997;65(2):349-57.

70. Bontempi EJ, Frasch ACC, Henriksson J, Pettersson U. Trypanosoma cruzi exoantigen is a member of a 160 kDa gene family. Parasitology. 1995;110(Pt 1):61-9.

71. De Souza W, De Carvalho TMU, Barrias ES. Review on Trypanosoma cruzi: Host cell interaction. International Journal of Cell Biology. 2010;2010:295394.

72. García EA, Ziliani M, Agüero F, Bernabó G, Sánchez DO, Tekiel V. TcTASV: A novel protein family in Trypanosoma cruzi identified from a subtractive trypomastigote cDNA library. PLoS Negl Trop Dis. 2010;4(10):e841.

73. Magdesian MH, Tonelli RR, Fessel MR, Silveira MS, Schumacher RI, Linden R, et al. A conserved domain of the gp85/trans-sialidase family activates host cell extracellular signal—regulated kinase and facilitates Trypanosoma cruzi infection. Exp Cell Res. 2007;313(1):210-8.

74. Tonelli RR, Torrecilhas AC, Jacysyn JF, Juliano MA, Colli W, Alves MJM. In vivo infection by Trypanosoma cruzi: The conserved FLY domain of the gp85/trans—sialidase family potentiates host infection. Parasitology. 2011;138(4):481-92.

75. Todeschini AR, Dias WB, Girard MF, Wieruszeski JM, Mendonça-Previato L, Previato JO. Enzymatically Inactive trans-Sialidase from Trypanosoma cruzi Binds Sialyl and $\beta$ —Galactopyranosyl Residues in a Sequential Ordered Mechanism. J Biol Chem. 2004;279(7):5323-8.

76. Cremona ML, Campetella O, Sánchez DO, Frasch ACC. Enzymically inactive members of the trans-sialidase family from Trypanosoma cruzi display $\beta$ — galactose binding activity. Glycobiology.1999;9(6):581-7.

77. Nardy AFFR, Freire-de-Lima CG, Pérez AR, Morrot A. Role of Trypanosoma cruzi Trans-sialidase on the escape from host immune surveillance. Front Microbiol. 2016;7(348).

78. Vimr E, Lichtensteiger C. To sialylate, or not to sialylate: that is the question. Trends Microbiol. 2002;10(6):254-7.

79. Erdmann H, Steeg C, Koch—Nolte F, Fleischer B, Jacobs T. Sialylated ligands on pathogenic Trypanosoma cruzi interact with Siglec—E (sialic acid— binding Ig-like lectin-E). Cell Microbiol. 2009; 1(11):1600-1611.

80. Tardieux I, Webster P, Ravesloot J, Boron W, Lunn JA, Heuser JE, et al. Lysosome recruitment and fusion are early events required for trypanosome invasion of mammalian cells. Cell. 1992;71(7):1117-30.

81. Albertti LAG, Macedo AM, Chiari E, Andrews NW, Andrade LO. Role of host lysosomal associated membrane protein (LAMP) in Trypanosoma cruzi invasion and intracellular development. Microbes Infect. 2010;12(10):784-9.

82. Rubin—de-Celis SSC, Uemura H, Yoshida N, Schenkman S. Expression of trypomastigote trans—sialidase in metacyclic forms of Trypanosoma cruzi increases parasite escape from its parasitophorous vacuole. Cell Microbiol. 2006;8(12):1888-98.

83. Hall BF, Webster P, Ma AK, Joiner KA, Andrews NW. Desialylation of lysosomal membrane glycoproteins by trypanosoma cruzi: A role for the surface neuraminidase in facilitating parasite entry into the host cell cytoplasm. J Exp Med. 1992;176(2):313-25.

84. Andrews NW, Whitlow MB. Secretion by Trypanosoma cruzi of a hemolysin active at low pH. Mol Biochem Parasitol. 1989;33(3):249-56.

85. Giddings OK, Eickhoff CS, Sullivan NL, Hoft DF. Intranasal vaccinations with the trans-sialidase antigen plus CpG adjuvant induce mucosal immunity protective against conjunctival Trypanosoma cruzi challenges. Infect Immun. 2010;78(3):1333-8.

86. Bontempi IA, Vicco MH, Cabrera G, Villar SR, González FB, Roggero EA, et al. Efficacy of a trans-sialidase-ISCOMATRIX subunit vaccine candidate to protect against experimental Chagas disease. Vaccine. 2015;33(10):1274-83.

87. Fontanella GH, De Vusser K, Laroy W, Daurelio L, Nocito AL, Revelli S, et al. Immunization with an engineered mutant trans-sialidase highly protects mice from experimental Trypanosoma cruzi infection: A vaccine candidate. Vaccine. 2008;26(19):2322-34

88. Gao W, Pereira MA. Trypanosoma cruzi trans—-sialidase potentiates T cell activation through antigen—presenting cells: Role of IL—6 and Bruton's tyrosine kinase. Eur J Immunol. 2001;31:1503-1512.

89. Freitas AA, Rocha B. Population Biology of Lymphocytes: The Flight for Survival. Annu Rev Immunol. 2000 Apr;18(1):83-111.

90. Montaudouin C, Anson M, Hao Y, Duncker S V., Fernandez T, Gaudin E, et al. Quorum Sensing Contributes to Activated IgM—Secreting B Cell Homeostasis. J Immunol. 2013;190(1):106-14.

91. Pereira—Chioccola VL, Acosta—Serrano A, De Almeida IC, Ferguson MAJ, Souto—Padron T, Rodrigues MM, et al. Mucin—like molecules form a negatively charged coat that protects Trypanosoma cruzi trypomastigotes from killing by human anti-a—galactosyl antibodies. J Cell Sci. 2000;113(Pt 7):1299-307.

92. Buscaglia CA, Campo VA, Frasch ACC, Di Noia JM. Trypanosoma cruzi surface mucins: host-dependent coat diversity. Nature reviews. Microbiology. 2006;4(3):229-36.

93. Freire-de-Lima L, Alisson-Silva F, Carvalho ST, Takiya CM, Rodrigues MM, DosReis GA, et al. Trypanosoma cruzi subverts host cell sialylation and may compromise antigen—specific CD8+ T cell responses. J Biol Chem. 2010 Apr;285(18):13388-96.

94. Pitcovsky TA, Buscaglia CA, Mucci J, Campetella O. A Functional Network of Intramolecular Cross-Reacting Epitopes Delays the Elicitation of Neutralizing Antibodies to Trypanosoma cruzi trans -Sialidase. J Infect Dis. 2002;186(3):397-404.

95. Mucci J, Lantos AB, Buscaglia CA, Leguizamón MS, Campetella O. The Trypanosoma cruzi Surface, a Nanoscale Patchwork Quilt. Vol. 33, Trends in Parasitology. Elsevier Ltd; 2017. p. 102-12. 
96. Wizel B, Garg N, Tarleton RL. Vaccination with trypomastigote surface antigen 1-encoding plasmid DNA confers protection against lethal Trypanosoma cruzi infection. Infect Immun. 1998;66(11):5073-81.

97. Bustamante J, Tarleton R. Reaching for the holy grail: Insights from infection/cure models on the prospects for vaccines for Trypanosoma cruzi infection. Mem Inst Oswaldo Cruz. 2015;110(3):445-51.

98. Cazorla SI, Frank FM, Malchiodi EL. Vaccination approaches against Trypanosoma cruzi infection. Expert Review of Vaccines. Expert Rev Vaccines. 2009;8(7):921-935

99. Eickhoff CS, Vasconcelos JR, Sullivan NL, Blazevic A, Bruna—Romero O, Rodrigues MM, et al. Co—administration of a plasmid DNA encoding IL-15 improves long —-term protection of a genetic vaccine against Trypanosoma cruzi. PLoS Negl Trop Dis. 2011;5(3):e983.

100. Fralish BH, Tarleton RL. Genetic immunization with LYT1 or a pool of trans-sialidase genes protects mice from lethal Trypanosoma cruzi infection. Vaccine. 2003 Jun;21(21-22):3070-80.

101. Chen X, Andreana PR, Wang PG. Carbohydrates in transplantation. Current Opinion in Chemical Biology. 1999;3(6):650—658.

102. Risso MG, Pitcovsky TA, Caccuri RL, Campetella O, Leguizamón MS. Immune system pathogenesis is prevented by the neutralization of the systemic trans—-sialidase from Trypanosoma cruzi during severe infections. Parasitology. 2007;134(Pt 4):503-10.

103. Schalk JAC, Mooi FR, Berbers GAM, Van Aerts LAGJM, Ovelgönne H, Kimman TG. Preclinical and clinical safety studies on DNA vaccines. Hum Vaccin. 2006;2(2):45-53.

104. Millar AE, Wleklinski-Lee M, Kahn SJ. The surface protein superfamily of Trypanosoma cruzi stimulates a polarized Thl response that becomes anergic. J Immunol. 1999;162(10):6092-9.

105. Clem AS. Fundamentals of vaccine immunology. Journal of Global Infectious Diseases. Wolters Kluwer — Medknow Publications; 2011;3(1):73-78.

106. Vaccine Types | NIH: National Institute of Allergy and Infectious Diseases.2019.

107. Hoft DF, Eickhoff CS, Giddings OK, Vasconcelos JRC, Rodrigues MM. Trans —-Sialidase Recombinant Protein Mixed with CpG MotifContaining Oligodeoxynucleotide Induces Protective Mucosal and Systemic Trypanosoma cruzi Immunity Involving CD8 + CTL and B CellMediated Cross—Priming. J Immunol. 2007;179(10):6889-900.

108. Prochetto E, Roldán C, Bontempi IA, Bertona D, Peverengo L, Vicco MH, et al. Trans—sialidase-based vaccine candidate protects against Trypanosoma cruzi infection, not only inducing an effector immune response but also affecting cells with regulatory/ suppressor phenotype. Oncotarget. 2017;8(35):58003-20.

109. Sanchez Alberti A, Bivona AE, Cerny N, Schulze K, Weißmann S, Ebensen T, et al. Engineered trivalent immunogen adjuvanted with a sting agonist confers protection against trypanosoma cruzi infection. npj Vaccines. 2017;2(9).

110. Sanchez Alberti A, Bivona AE, Cerny N, Schulze K, Weißmann S, Ebensen T, et al. Engineered trivalent immunogen adjuvanted with a sting agonist confers protection against trypanosoma cruzi infection. npj Vaccines. 2017;2(1).

111. Costa F, Franchin G, Pereira—Chioccola VL, Ribeirão M, Schenkman S, Rodrigues MM. Immunization with a plasmid DNA containing the gene of trans-sialidase reduces Trypanosoma cruzi infection in mice. Vaccine. 1998;16(8):768-74.

112. Vasconcelos JRC, Boscardin SB, Hiyane MI, Kinoshita SS, Fujimura AE, Rodrigues MM. A DNA—priming protein—boosting regimen significantly improves type 1 immune response but not protective immunity to Trypanosoma cruzi infection in a highly susceptible mouse strain. Immunol Cell Biol. 2003;81(2):121-9.

113. Machado A V., Cardoso JE, Claser C, Rodrigues MM, Gazzinelli RT, Bruna-Romero O. Long-term protective immunity induced against Trypanosoma cruzi infection after vaccination with recombinant adenoviruses encoding amastigote surface protein —2 and trans—sialidase. Hum Gene Ther. 2006;17(9):898-908.

114. Sanchez Alberti A, Bivona AE, Matos MN, Cerny N, Schulze K, Weißmann S, et al. Mucosal Heterologous Prime/Boost Vaccination Induces Polyfunctional Systemic Immunity, Improving Protection Against Trypanosoma cruzi. Front Immunol. 2020;11:128.

115. Bivona AE, Alberti AS, Cerny N, Trinitario SN, Malchiodi EL. Chagas disease vaccine design: the search for an efficient Trypanosoma cruzi immune - mediated control. Biochim Biophys Acta — Mol Basis Dis. 2020;1866(5):165658.

116. Rodríguez-Morales O, Monteón—Padilla V, Carrillo—Sánchez SC, Rios—Castro M, Martínez—Cruz M, Carabarin—Lima A, et al. Experimental Vaccines against Chagas Disease: A Journey through History. J Immunol Res. 2015;2015:489758.

117. Pulendran B, Ahmed R. Immunological mechanisms of vaccination. Nature Immunology. Nature Publishing Group. 2011;12(6):509-17.

118. Harandi Ali M, Sanchez Joaquin, Eriksson Kristina, Holmgren Jan. Recent Developments in Mucosal Immunomodulatory Adjuvants . Curr Opin Investig Drugs. 2003;4(2):156-61.

119. Arce-Fonseca M, Rios—Castro M, Del Carmen Carrillo—Sánchez S, Martínez—Cruz M, Rodríguez—Morales O. Prophylactic and therapeutic DNA vaccines against Chagas disease. Parasites and Vectors. 2015;8:121.

120. Dumonteil E, Bottazzi ME, Zhan B, Heffernan MJ, Jones K, Valenzuela JG, et al. Accelerating the development of a therapeutic vaccine for human Chagas disease: Rationale and prospects.Expert Review of Vaccines. Expert Rev Vaccines; 2012;11(9):1043-1055. 